\title{
Candida sake
}

National Cancer Institute

\section{Source}

National Cancer Institute. Candida sake. NCI Thesaurus. Code C127698.

A species of yeast in the family Trichocomaceae. C. sake is rarely pathogenic but has been identified as a causative agent of spondylodiscitis, fungal endocarditis, peritonitis, and bloodstream infection. 